\title{
e-Migrinter
}

6 | 2010

Rroms \& Gens du Voyage

\section{Rroms et Gens du Voyage : nos voisins « nomades »}

\section{Céline Bergeon}

\section{(2) OpenEdition}

Journals

Édition électronique

URL : https://journals.openedition.org/e-migrinter/1430

DOI : $10.4000 /$ e-migrinter. 1430

ISSN : 1961-9685

\section{Éditeur}

UMR 7301 - Migrinter

\section{Édition imprimée}

Date de publication : 15 octobre 2010

Pagination : 2-4

ISSN : 1961-9685

\section{Référence électronique}

Céline Bergeon, «Rroms et Gens du Voyage : nos voisins « nomades » », e-Migrinter [En ligne], 6 | 2010,

mis en ligne le 16 janvier 2019, consulté le 20 mai 2021. URL : http://journals.openedition.org/e-

migrinter/1430 ; DOI : https://doi.org/10.4000/e-migrinter.1430 


\section{ÉDITORIAL}

\section{Rroms et Gens du Voyage : nos voisins « nomades »}

\section{Céline Bergeon}

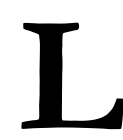

es événements survenus au cours de l'été 2010 en France, montrent combien les rapports entre populations sédentaires et circulantes restent problématiques. Ces relations conflictuelles illustrent parfaitement les tensions que peut procurer « la rencontre » des modes de vie. Ce numéro spécial de la revue e-migrinter sur les

Gens du Voyage s'intéresse particulièrement à définir une approche re-contextualisée de la mobilité de ces familles, trop souvent considérée comme « sans objectif ». Les auteurs s'attachent à étudier les relations entre la circulation traditionnelle et les dispositifs d'accueil proposés aux Rroms, qui sont soumis à une législation spécifique. Ils réinterrogent ainsi l'inscription sociale et spatiale des familles dans l'espace local.
Leur présence remonte au $14^{\text {ème }}$ siècle mais leur reconnaissance par les Gadjé c'est-à-dire ceux qui ne sont pas reconnus comme "Gens du Voyage » - reste encore marginale et difficile. Les Gens du Voyage représentent en Europe une population d'environ douze millions de personnes (Atlas des minorités en Europe, 2005). En France, des estimations peu fiables, notamment du fait du caractère aléatoire de la mobilité et de l'interdiction de production de données ethniques, chiffrent les Gens du Voyage à 250000 personnes environ ${ }^{1}$. La double appellation du titre de ce numéro, "Rroms et Gens du Voyage », introduit une des orientations de ce numéro spécial, qui vise une appréhension contemporaine de cette population, au regard de l'évolution de leur situation depuis l'après-guerre. Et c'est bien cette évolution qui est au centre des préoccupations des chercheurs qui ont contribué à ce numéro.

Quel est le chemin parcouru (ou non) dans la considération des Gens du Voyage au sein des espaces nationaux? Le voyage est-il une pratique révolue? Par la revisite d'un de ses textes, écrit dans les années 1980, Jean-Pierre Liégeois nous invite à constater la stagnation de la reconnaissance et de l'accueil des populations circulantes dans l'espace local. Il présente ainsi la situation telle qu'elle se présente avant l'introduction, dans la législation, du stationnement des familles, et montre qu'au lieu d'instaurer un climat d'hospitalité envers les Gens du Voyage, la législation, relayée par la désobéissance législative des

\footnotetext{
1 Source : Rapport Delevoye «Accueil des Gens du Voyage », 1997. Sénat, 7 novembre 1997, nº 283.
} 
collectivités locales, ne font qu'entretenir le rejet auquel sont confrontées les familles.

Le deuxième texte, écrit par Marion Salin et Céline Bergeon s'inscrit dans une réflexion sur les dénominations créés par l'administration et celles utilisées par les acteurs eux-mêmes dans leur vie quotidienne. Par le biais d'une analyse comparée de données de terrain, elles expliquent dans leur article, le jeu des identifications et des appartenances, mobilisé dans le rapport à l'Autre. Elles interrogent ainsi l'unité de la population dans le même temps qu'elles reprécisent l'ensemble des catégorisations au regard des réalités observées sur leur terrain de recherche respectif.

Cette relation à l'altérité est également discutée dans le texte de Lamia Missaoui, qui pointe la récurrente ethnicisation des pratiques des gitans. Pour sa réflexion, elle mobilise des données issues de trois terrains : l'Espagne, la France et l'Italie, et illustre cette ethnicisation par le biais de l'appréhension des pratiques sanitaires, souvent considérées comme spécifiques et anarchiques chez cette population.

Le texte de Céline Bergeon provient directement de ses recherches effectuées pendant sa thèse sur l'articulation entre les politiques publiques de stationnement et la circulation traditionnelle des Gens du Voyage. Elle pointe l'inapplication de la loi de 2000 concernant l'accueil et le stationnement des Rroms dans le même temps qu'elle interroge les effets directs de cette législation sur les pratiques circulatoires. A l'aide d'entretiens effectués dans la région Poitou-Charentes en France et en région wallonne en Belgique, elle met en lumière les comportements dynamiques et les initiatives circulatoires développés par les familles pour perpétuer leur mobilité.
La deuxième partie de ce numéro s'intéresse particulièrement au rôle de la religion dans la reconnaissance des Gens du Voyage mais également dans la poursuite de la circulation. Le texte de Régis Laurent nous invite à la lecture de la naissance du mouvement pentecôtiste chez les familles Rroms. Il engage notamment une réflexion sur les Missions Tsiganes Itinérantes (MTI) et explique pertinemment l'impact de ces réunions sur la visibilité des Gens du Voyage en France dans le même temps qu'il élève ce mouvement pentecôtiste en tant que "prestation compensatoire» face aux lacunes de l'Etat en termes de considération sociale.

Le dernier texte, écrit Julia Peyron, permet finalement de comprendre cet " éveil religieux» au regard de l'évolution de la situation des Gens du Voyage en France depuis l'après-guerre. Elle replace ainsi l'impact des modifications, tant économiques que sociales subies par les familles, dans cet essor de la religion chez les populations Rroms.

La dernière partie du numéro, comme à son habitude, présente les rubriques de la $V$ ie du Laboratoire ainsi que les Notes de lecture. Sont également présentées les soutenances des travaux de thèse novateurs de Caroline Rozenholc (Lire le lien pour dire la ville. Florentin : une mise en perspective d'un quartier de Tel Aviv dans la mondialisation (2005-2009)) et de Christian Wali Wali (Les réfugiés congolais au Gabon. Modes de circulation et d'installation dans un espace frontalier).

Hélène Simon-Lorière offre ensuite un compte-rendu de la journée d'étude «Mémoires et migrations: le cas des populations juives maghrébines en situations post-coloniales », qui s'est déroulée le 11 mars 2010 à la MSHS de Poitiers. AnneCécile Hoyez nous propose également un compte-rendu du colloque «Migrants, santé 
et expériences de la discrimination ", également organisé à la MSHS de Poitiers, le 12 Mars 2010.

Deux ouvrages récemment publiés (2009) sont recensés : Aux nouvelles frontières de l'Europe. L'aventure incertaine des Sénégalais au Maroc (recension de Gunhild Odden), Des femmes sur les routes. Voyages au féminin entre l'Afrique et la Méditerranée (recension de AnneLaure Counilh).
Avant de laisser partir la caravane de la réflexion, je souhaite remercier les auteurs pour leur participation à ce numéro spécial ainsi que pour leur patience, face aux aléas inhérents à sa réalisation. Merci également à Cédric Audebert, responsable de la revue, pour m'avoir donné la possibilité de le réaliser ainsi qu'à l'équipe du comité de rédaction.
Céline Bergeon

Doctorante en géographie

Migrinter - UMR 6588

CNRS /Université de Poitiers celine.bergeon@univ-poitiers.fr 